\section{Irene Favier \\ Joost Haan \\ Michel D. Ferrari}

\title{
Chronic cluster headache: a review
}

Received: 18 October 2004

Accepted in revised form: 9 December 2004

Published online: 25 January 2005

I. Favier • J. Haan • M.D. Ferrari (凶)

Department of Neurology, K5-Q

Leiden University Medical Centre,

PO Box 9600, 2300 RC Leiden,

The Netherlands

e-mail: m.d.ferrari@lumc.nl

Tel.: +31-71-5262895

Fax: +31-71-5248253

J. Haan

Rijnland Hospital Leiderdorp,

The Netherlands

\begin{abstract}
Cluster headache $(\mathrm{CH})$ is a rare but severe headache disorder characterised by repeated unilateral head pain attacks accompanied by ipsilateral autonomic features. In episodic $\mathrm{CH}$, there are periods of headache attacks with pain-free intervals of weeks, months or years in between. A minority of patients have the chronic form, without pain-free intervals between the headache attacks. Chronic $\mathrm{CH}$ can occur as primary or secondary chronic $\mathrm{CH}$; the rarest form is
\end{abstract}

episodic $\mathrm{CH}$ arising from chronic $\mathrm{CH}$. In this article, we give a review of the chronic forms of $\mathrm{CH}$ and focus on demographics, clinical manifestations, social habits, predictive factors, head injury, genetics, neuroimaging and therapy. It is remarkable that little is known about risk factors that make $\mathrm{CH}$ chronic.

Key words Chronic cluster headache $\cdot$ Review

\section{Introduction}

Cluster headache $(\mathrm{CH})$ is characterised by short-lasting, unilateral severe pain attacks, usually located in the orbitotemporal region, accompanied by ipsilateral autonomic phenomena and/or restlessness or agitation [1]. Untreated, the pain lasts $15 \mathrm{~min}$ to $3 \mathrm{~h}$ and can occur from once every other day to 8 times a day. It is an excruciating pain, driving some patients to thoughts of suicide.

In episodic $\mathrm{CH}(\mathrm{ECH})$, the attacks occur in cluster periods lasting from one week to one year and are separated by remission periods of at least one month (Table 1). In chronic $\mathrm{CH}(\mathrm{CCH})$ the attacks occur almost every day for more than one year without remission or with remissions lasting less than one month. The chronic form can be unremitting from onset, primary chronic cluster headache $(\mathrm{PCCH})$, or can evolve from the episodic form, secondary chronic cluster headache (SCCH). The rarest variety is the secondary episodic form (SECH), which begins as chronic and becomes episodic.

In this review, we give an overview of demographics, clinical manifestations, social habits, predictive factors, head injury, genetics, neuroimaging and therapy of $\mathrm{CCH}$. In the separate sections, we will first compare ECH with $\mathrm{CCH}$, followed by a comparison of $\mathrm{PCCH}$ and $\mathrm{SCCH}$.

\section{Demographics}

The exact prevalence of $\mathrm{CH}$ (and its subforms) is uncertain. In some epidemiological surveys, the prevalence of $\mathrm{CH}$ varies from 56 to 401 per 100000 [2]. The highest prevalence of 401 per 100000 was found in a study in which the diagnosis of $\mathrm{CH}$ was based on a review of 
Table 1 Diagnostic criteria for $\mathrm{CH}$ [1]

CH At least 5 attacks fulfilling criteria B-D
A. Severe or very severe unilateral orbital, supraorbital and/or
temporal pain lasting $15-180$ min if untreated
C. Headache is accompanied by at least one of the following:
1. Ipsilateral conjunctival injection and/or lacrimation
2. Ipsilateral nasal congestion and/or rhinorrhoea
3. Ipsilateral eyelid oedema
4. Ipsilateral forehead and facial sweating
5. Ipsilateral miosis and/or ptosis
6. A sense of restlessness or agitation
D. Attacks have a frequency from one every other day to
8 per day
E. Not attributed to another disease
ECH
A. Attacks fulfilling criteria A-E for $\mathrm{CH}$
B. At least two cluster periods lasting $7-365$ days and
separated by pain-free remission periods of $\geq 1$ month
$\mathrm{CCH}$ A. Attacks fulfilling criteria A-E for $\mathrm{CH}$
A. Attacks recur $>1$ year without remission periods or with
remission periods lasting <1 month

charts from patients who had been seen and diagnosed by a wide variety of clinicians [3]. So, this high figure may be biased.

The episodic form of $\mathrm{CH}$ is much more prevalent than the chronic form. The exact ratio between chronic and episodic $\mathrm{CH}$, however, is unknown. Figures in the literature differ [4-6] (Table 2), probably because there is a difference in patient selection. Within the group of patients with $\mathrm{CCH}$, the prevalence of the subgroups $(\mathrm{PCCH}$, $\mathrm{SCCH}, \mathrm{SECH})$ is also not exactly known. In a follow-up study of $109 \mathrm{CCH}$ patients during at least 5 years, 64\% could be classified as $\mathrm{PCCH}$ and $36 \%$ as SCCH [7].

As to the course of $\mathrm{CH}$, Pearce [8] conducted a followup study of 101 patients with ECH and 7 patients with $\mathrm{CCH}$ during 16 years. Four patients $(3.96 \%)$ in the episodic group changed to a chronic pattern, whereas in the chronic group, 2 patients $(28.6 \%)$ changed to an episodic pattern. Another study followed 189 patients with $\mathrm{CH}$ over a period longer than 10 years [9]. Almost $13 \%$ of ECH patients became secondarily chronic and $32.6 \%$ of $\mathrm{CCH}$ patients became secondarily episodic.

In 1956, Horton [10] reported a male-to-female ratio of $\mathrm{CH}$ of 6.7:1 and this was used in clinical practice for years. Recently, the male-to-female ratio was found to be much lower, namely 2.5:1 [5]. This decrease in ratio might be explained by the fact that specific male behavioural traits are possible cluster triggers and that more women are taking over these traits. Also, more women are contributing to household incomes and therefore seek treatment sooner. Another explanation might be that in the past, many women
Table 2 Episodic-to-chronic ratio

\begin{tabular}{lrr}
\hline Study & $\begin{array}{r}\text { Number } \\
\text { of patients }\end{array}$ & $\begin{array}{r}\text { Episodic-to- } \\
\text { chronic ratio }\end{array}$ \\
\hline Manzoni (1997) [4] & 482 & $7.5: 1$ \\
Bahra et al. (2002) [5] & 230 & $4: 1$ \\
Van Vliet et al. (2003) [6] & 1163 & $3.5: 1$ \\
\hline
\end{tabular}

with $\mathrm{CH}$ were first diagnosed with migraine, because of atypical features of the $\mathrm{CH}$, such as longer duration of an attack. A male to female ratio of 3.6:1 was found for $\mathrm{ECH}$ and 4.2:1 for $\mathrm{CCH}$ [4]. Another study found a male to female ratio of 3.2:1 in PCCH and 2.4:1 in SCCH [11].

Mean age at onset appeared to be later in $\mathrm{CCH}$ than in ECH: 38 vs. 32 years [6]. Mean age at onset was later in $\mathrm{PCCH}$ compared to SCCH: approximately 37 vs. 29 years $[11,12]$.

In conclusion, the exact prevalence of $\mathrm{CH}$ and its subforms is uncertain, but it is clear that episodic $\mathrm{CH}$ is much more prevalent than chronic $\mathrm{CH}$. There is a male preponderance in $\mathrm{CH}$, especially in the chronic form. In chronic $\mathrm{CH}$, the mean age at onset appeared to be about 6 years later than in episodic $\mathrm{CH}$. The mean age at onset is especially late in primary chronic $\mathrm{CH}$.

\section{Clinical manifestations}

The diagnostic criteria for $\mathrm{CH}$ do not differentiate between $\mathrm{ECH}$ and $\mathrm{CCH}$ in the clinical features of the attacks. The distinction is only made in the occurrence and duration of remission periods, but clinical studies also found some differences in the characteristics of $\mathrm{ECH}$ and $\mathrm{CCH}$.

First, patients with $\mathrm{CCH}$ appear to have a mild, continuous headache between the attacks more often than patients with ECH [6]. Second, a significant difference in the site of pain appears to exist [5]. In both forms the site of pain was predominantly retro-orbital and temporal, but in $\mathrm{CCH}$, more patients reported pain also in the upper teeth, jaw, cheek, ear and shoulder. Besides, in $\mathrm{CCH}$ there was more often a side change of the pain. Third, differences in autonomic features were found between ECH and $\mathrm{CCH}$. Lacrimation is the most often reported symptom in both conditions, but rhinorrhoea occurred significantly less in $\mathrm{CCH}$. Osmophobia occurred more in $\mathrm{CCH}$. Finally, the reported attack duration between $\mathrm{ECH}$ and $\mathrm{CCH}$ was shorter in the chronic group.

There are also some differences in characteristics between PCCH and SCCH [11]. First, patients with PCCH more often reported right-sided pain than patients with 
$\mathrm{SCCH}$, a finding that is not easily explained. Second, in $\mathrm{PCCH}$ and SCCH, attack duration was most often between 15 and $120 \mathrm{~min}$, but there was a statistically significant larger proportion of patients with $\mathrm{SCCH}$ who reported attacks lasting 120-180 min. Finally, patients with SCCH were more likely to have their headache associated with lacrimation, nasal congestion, rhinorrhoea and ptosis while patients with $\mathrm{PCCH}$ more frequently reported facial sweating and eyelid oedema.

In conclusion, there are some clinical differences between episodic and chronic $\mathrm{CH}$ and also between the two chronic forms.

\section{Social habits}

Some studies have looked at lifestyle habits in episodic $v s$ chronic $\mathrm{CH}$. Up to $90 \%$ of $\mathrm{CH}$ patients are smokers or former smokers [12] and there seem to be some differences between the episodic and chronic forms (Tables 3 and 4). In an Italian study, more male $\mathrm{CCH}$ patients smoked compared to $\mathrm{ECH}$ patients and the chronic patients also smoked more cigarettes a day [12]. Comparing the two chronic forms, there were more and also more heavy smokers in the SCCH group [11].

Table 3 Social habits in ECH vs. CCH [12]

\begin{tabular}{lrr}
\hline Social habit & ECH, \% & CCH, \% \\
\hline Smoking habit & & \\
$\quad$ No. of patients & 78.9 & 87.8 \\
$\quad>20$ cig/day & 57.8 & 66.7 \\
Alcohol intake & & \\
$\quad$ No. of patients & 84.2 & 90.2 \\
$\quad$ >100 g/day & 19.2 & 29.7 \\
Coffee intake & & \\
$\quad$ No. of patients & 94.4 & 36.6 \\
$\quad>6$ cups/day & 7.3 & \\
\hline
\end{tabular}

Table 4 Social habits in $\mathrm{PCCH}$ vs. SCCH [11]

\begin{tabular}{lrr}
\hline Social habit & PCCH, \% & SCCH, \% \\
\hline Smoking habit & & \\
$\quad$ No. of patients & 65.8 & 87.1 \\
>20 cig/day & 21.1 & 48.4 \\
Alcohol intake & & \\
$\quad$ No. of patients & 76.3 & 64.5 \\
50-100 g/day & 27.6 & \\
Coffee intake & & 90.3 \\
$\quad$ No. of patients & 89.5 & 32.3 \\
5-7 cups/day & 57.9 & \\
\hline
\end{tabular}

There were a few more alcohol drinkers in $\mathrm{CCH}$ compared to $\mathrm{ECH}$, but the chronic patients were evidently heavier drinkers [12]. PCCH patients were more frequently heavy drinkers compared to SCCH patients [11].

A minor difference was found in the number of $\mathrm{ECH}$ and $\mathrm{CCH}$ patients consuming coffee, but the chronic patients drank more cups of coffee a day [12]. The percentage of regular coffee drinkers was the same in both chronic conditions, however $\mathrm{PCCH}$ patients drank more cups of coffee a day [11].

In conclusion, lifestyle habits such as smoking and the consumption of alcohol or coffee are common habits in $\mathrm{CH}$, especially in chronic $\mathrm{CH}$. Comparing the two chronic conditions, smoking is a more common habit in $\mathrm{SCCH}$ patients while consuming alcohol or coffee is more common among $\mathrm{PCCH}$ patients.

\section{Secondary chronic cluster headache: predictive factors}

Three factors were discovered that seemed to predict a shift from ECH to $\mathrm{CCH}$ [9]. Firstly, the shift was associated with the duration of the disease. In $20.5 \%$ of episodic patients with a course of $\mathrm{CH}$ longer than 20 years, there was a shift towards the chronic form, versus a shift in $9.4 \%$ of patients with a shorter course than 20 years. Secondly, a late age at onset appeared to predict a pattern change. Mean age at onset was 27.1 years in $\mathrm{ECH}$, while the mean age at onset was 34.9 years in SCCH. Thirdly, male sex was slightly related to a shift to a chronic condition: in $\mathrm{SCCH}$, the percentage of females was $9.1 \%$ and the percentage of males was $13.6 \%$.

The characteristics of cluster and remission periods were also found to be predictive factors in the shift from $\mathrm{ECH}$ to SCCH (Table 5). More SCCH patients reported cluster periods lasting more than 8 weeks before the $\mathrm{CH}$ became chronic, compared to ECH patients who stayed episodic [13]. Also, a larger proportion of SCCH patients reported remission periods lasting less than 6 months. More $\mathrm{SCCH}$ patients reported more than one cluster period a year and more frequently reported sporadic attacks.

Table 5 Characteristics of cluster and remission periods in $\mathrm{ECH}$ and $\mathrm{SCCH}[13]$

\begin{tabular}{lrr}
\hline & ECH, \% & SCCH, \% \\
\hline Cluster periods $>8$ weeks & 8.5 & 25 \\
Remission periods $<6$ months & 6.6 & 28.6 \\
More than 1 cluster/year & 18.2 & 28.6 \\
Sporadic attacks & 5 & 25 \\
\hline
\end{tabular}


In conclusion, factors that were found to predict a shift from episodic to chronic $\mathrm{CH}$ are: a longer course, a late age at onset, male sex, longer cluster periods, shorter remission periods, more cluster periods per year and more frequent sporadic attacks.

\section{Secondary episodic cluster headache: predictive factors}

Four factors were found that favoured the evolution of $\mathrm{CCH}$ into SECH [9]. The first one was the use of prophylactic treatment (usually lithium). Of the chronic patients who became secondary episodic, about $56 \%$ used prophylactic medication. The second factor was an earlier headache onset. $\mathrm{CH}$ onset was 26 years for SECH and almost 35 years for PCCH. Thirdly, duration of the disease longer than 20 years was positively related to the evolution from $\mathrm{CCH}$ to $\mathrm{ECH}$. Only in $46.6 \%$ of patients with $\mathrm{CCH}$ and a course longer than 20 years did the chronic form persist. Fourthly, male sex appeared to relate positively to a shift from $\mathrm{CCH}$ to $\mathrm{ECH}$ : all of the patients in the SECH group were men.

In conclusion, factors that were found to predict a shift from chronic to episodic $\mathrm{CH}$ are: the use of prophylactic treatment, an earlier age at onset, a longer course and male sex.

\section{Head injury}

Head injury and $\mathrm{CH}$ have been frequently associated. In a case-control study [14], significantly more $\mathrm{CH}$ patients had a previous head trauma compared to the control group (30.8\% vs. $15.8 \%$ ), and in another study, almost $37 \%$ of $\mathrm{CH}$ individuals reported head injury vs. almost $17 \%$ of age- and gender-matched migrainous controls [12]. Patients with $\mathrm{CCH}$ reported a head injury more often, whether with or without loss of consciousness, compared to patients with ECH (Table 6). Also, head injury occurred more often on the same side as the headache in chronic patients. Head injury preceded the onset of $\mathrm{CH}$ more often in chronic patients [11] than episodic patients [13].

Individuals with $\mathrm{PCCH}$ reported head injury in their history less frequently compared to $\mathrm{SCCH}$ [11], but in a

Table 6 Head injury in CH [11-13]

\begin{tabular}{lcccc}
\hline Head injury & $\mathrm{ECH}, \%$ & $\mathrm{CCH}, \%$ & $\mathrm{PCCH}, \%$ & $\mathrm{SCCH}, \%$ \\
\hline No. of patients & 35.9 & 54.7 & 34.2 & 54.8 \\
Pre-CH & 45.3 & 70.0 & 76.9 & 64.7 \\
\hline
\end{tabular}

higher percentage of $\mathrm{PCCH}$ patients, the head injury preceded onset of $\mathrm{CH}$. A significant difference was found in the average number of years elapsing between head injury and onset of $\mathrm{CH}$ when the analysis was restricted to headinjured males with loss of consciousness. The average latency period was 21.8 years for $\mathrm{PCCH}$ men and 5.5 years for SCCH men. Four of $28 \mathrm{SCCH}$ patients had a second head injury and in all these 4 patients, the second head injury preceded the evolution from episodic to chronic [13]. The mean latency period between the second head injury and the evolution into SCCH was 11.0 years.

In conclusion, many $\mathrm{CH}$ patients report a head injury in their medical history. The frequency of head injury is higher in chronic than episodic patients and also higher in $\mathrm{SCCH}$ patients compared to $\mathrm{PCCH}$ patients. In most chronic patients, the head injury preceded the onset of $\mathrm{CH}$.

\section{Genetics}

It has been suggested that there is a genetic influence in $\mathrm{CH}$. $\mathrm{CH}$ has been described in monozygotic twins and also in families in consecutive generations. In a French study [15], a positive family history was found in $10.75 \%$ of $\mathrm{CH}$ patients. Familial $\mathrm{CH}$ was found in $9.52 \%$ of $\mathrm{ECH}$ patients and in $20 \%$ of $\mathrm{CCH}$ patients; the difference was not statistically significant. Different forms of $\mathrm{CH}$ can occur within the same family. Spierings et al. [16] described a family with the occurrence of $\mathrm{CH}$ in three generations: an 8-yearold boy with PCCH, his 42-year-old father with $\mathrm{SCCH}$ and his 73-year-old paternal grandfather with ECH.

In conclusion, no difference in genetic factors seems to exist between the episodic and chronic form. Different forms of $\mathrm{CH}$ can occur in the same family.

\section{Neuroimaging}

PET studies in $\mathrm{CH}$ patients revealed that the ipsilateral inferior posterior hypothalamus is activated during a $\mathrm{CH}$ attack [17]. No difference was made between $\mathrm{CCH}$ and $\mathrm{ECH}$, because the ECH patients were used as controls while they were not in a cluster period.

With voxel-based morphometry, a significant structural difference in grey matter density bilateral in the inferior posterior hypothalamus was found between $\mathrm{CH}$ patients and healthy volunteers [18]. No comparison was made between $\mathrm{CCH}$ and $\mathrm{ECH}$ patients.

In conclusion, the difference between $\mathrm{ECH}$ and $\mathrm{CCH}$ in hypothalamic function and grey matter density has not been studied yet. 


\section{Therapy}

More patients with $\mathrm{ECH}$ than with $\mathrm{CCH}$ had success with oxygen: $78.8 \%$ vs. $68.4 \%$ [19]. The greatest difference was found when comparing ECH patients under 50 years of age $(92.9 \%)$ with $\mathrm{CCH}$ patients over 49 years of age $(57.1 \%) . \mathrm{CH}$ can also be treated with a hyperbaric form of oxygen. In a placebo-controlled study, the treatment of $\mathrm{CCH}$ patients with hyperbaric oxygen in 15 sessions every other day for 4 weeks was more effective than placebo [20]. The number of attacks and the analgesic consumption declined in the group treated with hyperbaric oxygen, while there was no change in the placebo group. However, it is difficult to treat patients with this therapy, because it requires hyperbaric chambers.

Patients with $\mathrm{CCH}$ responded well to the use of subcutaneous sumatriptan, but to a lesser extent than $\mathrm{ECH}$ patients: $72.9 \%$ of $\mathrm{ECH}$ patients were pain free within 15 min compared to $60 \%$ of $\mathrm{CCH}$ patients [21]. Also, $\mathrm{CCH}$ patients responded more slowly than patients with $\mathrm{ECH}$.

In an open-label study [22], intranasal sumatriptan was more effective in $\mathrm{ECH}$ than in $\mathrm{CCH}$, but only 4 patients with $\mathrm{CCH}$ and 6 with $\mathrm{ECH}$ participated. Within $30 \mathrm{~min}$, $42 \%$ of headache attacks improved in ECH patients compared to only $16 \%$ of headache attacks in $\mathrm{CCH}$ patients. In a placebo-controlled study [23], no difference in efficacy of sumatriptan nasal spray was found between episodic and chronic patients. Unfortunately, no percentages were given.

Dihydroergotamine was more effective for $\mathrm{ECH}$ than for $\mathrm{CCH}$ [24]: there was complete resolution in $73 \%$ of $\mathrm{ECH}$ patients and in $46 \%$ of $\mathrm{CCH}$ patients. Dihydroergotamine appeared to induce transformation from $\mathrm{CCH}$ to $\mathrm{ECH}$ : of the 17 patients with $\mathrm{CCH}$ who achieved complete success with dihydroergotamine, 3 experienced a transformation to $\mathrm{ECH}$.

In a double-blind crossover study, significantly more patients with ECH reported efficacy of oral zolmitriptan than placebo (46.8\% vs. 28.9\%) [25]. In $\mathrm{CCH}$ however, there was no significant difference.

In an open study with 48 patients [26], it was found that $\mathrm{ECH}$ patients more often improved than $\mathrm{CCH}$ patients on verapamil prophylaxis $(73 \%$ vs. $60 \%)$, but this difference was not significant. Headache relief was obtained after an average of 1.7 weeks in the episodic group and after an average of 5 weeks in the chronic group. The required average daily dose of verapamil was $354 \mathrm{mg}$ in $\mathrm{ECH}$ and $572 \mathrm{mg}$ in $\mathrm{CCH}$.

In an open study [27], 19 male $\mathrm{CH}$ patients (8 with $\mathrm{CCH}$ and 11 with $\mathrm{ECH})$ were treated with lithium. In all chronic patients, there was at least a $75 \%$ improvement within 2 weeks after starting the treatment. In the episodic patients, there was an average improvement of only $15 \%$ with no improvement in 3 patients. Lithium was compared with verapamil in a double-blind crossover trial in $\mathrm{CCH}$ patients [28]. It appeared that both medications were efficacious in preventing $\mathrm{CCH}$, without significant differences.

Methysergide appeared effective in approximately $65 \%$ of $\mathrm{ECH}$ patients and in only $20 \%$ of $\mathrm{CCH}$ patients [29].

In an open-label study with 77 episodic and 15 chronic patients, there was a marked relief with prednisone therapy in $76.6 \%$ of patients with $\mathrm{ECH}$ and in $40 \%$ of patients with $\mathrm{CCH}$ [29].

In an open-label study, topiramate rapidly induced cluster remission in $64.3 \%$ of $\mathrm{CCH}$ patients and in $50 \%$ of ECH patients [30]. All chronic patients and $75 \%$ of episodic patients had poor or no response to other preventive treatments.

Serum melatonin levels are reduced in $\mathrm{CH}$ patients during a cluster period $[31,32]$. In a double blind, placebo-controlled trial in $18 \mathrm{ECH}$ and $2 \mathrm{PCCH}$ patients, melatonin appeared only effective in the prophylaxis of $\mathrm{ECH}$ [33]. In another study, in $6 \mathrm{CCH}$ patients and $3 \mathrm{ECH}$ patients who did not react to conventional therapy, there was no effect of melatonin [34]. The lack of response in $\mathrm{CCH}$ may reflect a fundamental difference between the chronic and episodic condition.

In a placebo-controlled trial, capsaicin was superior to placebo in reducing headache severity when delivered twice a day in the ipsilateral nostril for seven days [35]. Episodic patients appeared to benefit more than chronic patients.

In $\mathrm{CCH}$ cases resistant to medical management, surgery could be a feasible option. Of 17 patients with intractable $\mathrm{CCH}$ who underwent a partial or complete section of the trigeminal nerve, $15(88 \%)$ had complete or near-complete relief of their $\mathrm{CH}$ in the immediate postoperative period [36]. Complete section produced better results than partial section, but this difference was not significant. Two patients had recurrence of the $\mathrm{CH}$ after initial complete relief.

In another study, $28 \mathrm{CCH}$ patients underwent in total 39 microvascular decompression procedures of the trigeminal nerve, alone or in combination with section and/or microvascular decompression of the nervus intermedius [37]. In 22 of 30 (73.3\%) first time procedures, there was a $50 \%$ relief or better. At follow-up, this success rate dropped to $46.6 \%$. Repeating the procedure was ineffective. Stimulation of the ipsilateral posterior hypothalamus with stereotactic implants in five patients with medically refractory $\mathrm{CCH}$ was successful [38]. All patients achieved complete pain relief. The relief of pain occurred in two patients after a couple of hours, in three patients in 1-4 weeks. Three patients remained pain free with prophylactic medication, the other two patients stayed pain free without medication. There were no adverse side effects of the stimulation and there were no acute complications from 
the electrode implant procedure. Of course, these results are from a limited number of patients. In a long-term follow-up study of a patient with bilateral hypothalamic stimulation, the stimulation appeared very successful, but there were some adverse events, consisting of transient vertigo and bradycardia [39]. Besides, the hypothalamus is important for internal metabolic homeostasis and circadian rhythms, so an extremely cautious patient selection for hypothalamic stimulation is mandatory. Recently, proposals for patient selection are published [40].

In conclusion, symptomatic treatment with oxygen and subcutaneous sumatriptan is more effective in ECH than in $\mathrm{CCH}$. Prophylactic medications are also more effective in $\mathrm{ECH}$ than in $\mathrm{CCH}$ with the exception of topiramate and especially lithium. Dihydroergotamine is more effective in $\mathrm{ECH}$, but appears to induce transformation from $\mathrm{CCH}$ to $\mathrm{ECH}$. Surgery could be a feasible option for $\mathrm{CCH}$ patients resistant to medical management. Stimulation of the posterior hypothalamus seemed to be very effective in medically refractory $\mathrm{CCH}$, but the results are from a very limited number of patients.

\section{Conclusions}

$\mathrm{CH}$ is a severe headache disorder. Especially its chronic forms are very disabling and difficult to treat. In approximately $4-13 \%$ of cases, the episodic condition can develop to a chronic form of $\mathrm{CH}$. It is remarkable that little is known about factors that influence the evolution of ECH to $\mathrm{CCH}$. Such knowledge can, however, be of great value, as it may lead to treatment or preventive measures to avoid this evolution. In our present review of (mainly retrospective) studies, three factors seemed to predict the shift from ECH to $\mathrm{CCH}$ : a longer course of $\mathrm{CH}$, a late age at onset and male sex. The influence of male sex may have been overestimated, as there were not many women examined in these studies. The role of a long duration of $\mathrm{CH}$ is also not very strong, because the longer the duration of a disease, the more time there is for a pattern change. The characteristics of cluster and remission periods also seemed to predict a shift from $\mathrm{ECH}$ to $\mathrm{CCH}$.

When comparing ECH with $\mathrm{CCH}$, there did not appear to be many clinical differences. The main difference we found was the effect of prophylactic medication, which is larger in $\mathrm{ECH}$ than in $\mathrm{CCH}$, with the exception of topiramate and lithium. Selection bias is a likely cause for these findings. It is striking that dihydroergotamine, although more effective in $\mathrm{ECH}$, appears to induce transformation from $\mathrm{CCH}$ to $\mathrm{ECH}$.

The comparison of $\mathrm{PCCH}$ with $\mathrm{SCCH}$ revealed a male preponderance in $\mathrm{PCCH}$, but not many clinical differences.

Not much is known about the pathophysiology of $\mathrm{CH}$. Even less is known about the chronic forms of $\mathrm{CH}$. Patients with $\mathrm{CCH}$ more often report a head injury and some studies point to differences in social habits between $\mathrm{ECH}$ and $\mathrm{CCH}$. These social habits are more often displayed by chronic patients. But are these habits secondary phenomena to the suffering of chronic $\mathrm{CH}$, or do they play a role in the onset? Also, are there more factors that could favour the development of chronic $\mathrm{CH}$, besides a head injury and lifestyle habits? For instance, does the frequent use of triptans play a role? Further research, for example by means of prospective and longitudinal studies, might lead to more insight in the pathophysiology of $\mathrm{CCH}$.

\section{References}

1. - (2004) The international classification of headache disorders, 2nd edn. Headache Classification Subcommittee of the International Headache Society. Cephalalgia 24[Suppl 1]:44-48

2. Russell MB (2004) Epidemiology and genetics of cluster headache. Lancet Neurol 3(5):279-283

3. Dodick DW, Rozen TD, Goadsby PJ, Silberstein SD (2000) Cluster headache. Cephalalgia 20(9):787-803

4. Manzoni GC (1997) Male preponderance of is progressively decreasing over the years. Headache 37(9):588-589
5. Bahra A, May A, Goadsby PJ (2002) Cluster headache. A prospective clinical study with diagnostic implications. Neurology 58(3):354-361

6. Van Vliet JA, Eekers PJE, Haan J, Ferrari MD (2003) Features involved in the diagnostic delay of cluster headache. J Neurol Neurosurg Psychiatry 74(8):1123-1125

7. Kunkel RS, Frame JR (1994) Chronic cluster headache. Long-term followup. In: Olesen J (ed.) Headache classification and epidemiology. Raven Press, New York, pp 113-116

8. Pearce JMS (1993) Natural history of cluster headache. Headache 33(5):253-256
9. Manzoni GC, Micieli G, Granella F, Tassorelli C, Zanferrari C, Cavallini A (1991) Cluster headache - course over ten years in 189 patients. Cephalalgia 11(4):169-174

10. Horton BT (1956) Histaminic cephalalgia: differential diagnosis and treatment. Proc Staff Meet Mayo Clin 31:325-333

11. Torelli P, Cologno D, Cademartiri C, Manzoni GC (2000) Primary and secondary chronic cluster headache: two separate entities? Cephalalgia 20(9):826-829 
12. Manzoni GC (1999) Cluster headache and lifestyle: remarks on a population of 374 male patients. Cephalalgia 19(2):88-94

13. Torelli P, Cologno D, Cademartiri C, Manzoni GC (2000) Possible predictive factors in the evolution of episodic to chronic cluster headache. Headache 40(10):798-808

14. Italian Cooperative Study Group on the Epidemiology of Cluster Headache (1995) Case-control study on the epidemiology of cluster headache I: Etiological factors and associated conditions. Neuroepidemiology 14(3):123-127

15. El Amrani M, Ducros A, Boulan P, Aidi S, Crassard I, Visy JM, TournierLasserve E, Bousser MG (2002) Familial cluster headache: a series of 186 index patients. Headache 42(10):974-977

16. Spierings ELH, Vincent AJPE (1992) Familial cluster headache: occurrence in three generations. Neurology 42(7):1399-1400

17. May A, Bahra A, Büchel C, Frackowiak RSJ, Goadsby PJ (2000) PET and MRA findings in cluster headache and MRA in experimental pain. Neurology 55(9):1328-1335

18. May A, Ashburner J, Büchel C, McGonigle DJ, Friston KJ, Frackowiak RSJ, Goadsby PJ (1999) Correlation between structural and functional changes in brain in an idiopathic headache syndrome. Nat Med 5(7):836-838

19. Kudrow L (1981) Response of cluster headache attacks to oxygen inhalation. Headache 21(1):1-4

20. Di Sabato F, Rocco M, Martelletti P, Giacovazzo M (1997) Hyperbaric oxygen in chronic cluster headaches: influence on serotonergic pathways. Undersea Hyperb Med 24(2):117-122

21. Göbel H, Lindner V, Heinze A, Ribbat M, Deuschl G (1998) Acute therapy for cluster headache with sumatriptan: Findings of a one-year long-term study. Neurology 51(3):908-911
22. Schuh-Hofer S, Reuter U, Kinze S, Einhäupl KM, Arnold G (2002) Treatment of acute cluster headache with $20 \mathrm{mg}$ sumatriptan nasal spray an open pilot study. J Neurol 249(1):94-99

23. Van Vliet JA, Bahra A, Martin V, Ramadan N, Aurora SK, Mathew NT, Ferrari MD, Goadsby PJ (2003) Intranasal sumatriptan in cluster headache. Randomized placebo-controlled double-blind study. Neurology 60(4):630-633

24. Magnoux E, Zlotnik G (2004) Outpatient intravenous dihydroergotamine for refractory cluster headache. Headache 44(3):249-255

25. Bahra A, Gawel MJ, Hardebo JE, Millson D, Breen SA, Goadsby PJ (2000) Oral zolmitriptan is effective in the acute treatment of cluster headache. Neurology 54(9):1832-1839

26. Gabai IJ, Spierings ELH (1989) Prophylactic treatment of cluster headache with verapamil. Headache 29(3):167-168

27. Ekbom K (1981) Lithium for cluster headache: review of the literature and preliminary results of long-term treatment. Headache 21(4):132-139

28. Bussone G, Leone M, Peccarisi C, Micieli G, Granella F, Magri M, Manzoni GC, Nappi G (1990) Double blind comparison of lithium and verapamil in cluster headache prophylaxis. Headache 30(7):411-417

29. Kudrow L (1980) The management of cluster headache. In: Kudrow L (ed.) Cluster headache. Oxford University Press, New York, pp 127-154

30. Láinez MJA, Pascual J, Pascual AM, Santonja JM, Ponz A, Salvador A (2003) Topiramate in the prophylactic treatment of cluster headache. Headache 43(7):784-789

31. Leone M, Bussone G (1993) A review of hormonal findings in cluster headache. Evidence for hypothalamic involvement. Cephalalgia 13(5):309-317
32. Leone M, Lucini V, D'Amico D, Moschiano F, Maltempo C, Fraschini F, Bussone G (1995) Twenty-four-hour melatonin and cortisol plasma levels in relation to timing of cluster headache. Cephalalgia 15(3):224-229

33. Leone M, D'Amico D, Moschiano F, Fraschini F, Bussone G (1996) Melatonin versus placebo in the prophylaxis of cluster headache: a doubleblind pilot study with parallel groups. Cephalalgia 16(7):494-496

34. Pringsheim T, Magnoux E, Dobson CF, Hamel E, Aubé M (2002) Melatonin as adjunctive therapy in the prophylaxis of cluster headache: A pilot study. Headache 42(8):787-792

35. Marks DR, Rapoport A, Padla D, Weeks R, Rosum R, Sheftell F, Arrowsmith F (1993) A double-blind placebo-controlled trial of intranasal capsaicin for cluster headache. Cephalalgia 13(2):114-116

36. Jarrar RG, Black DF, Dodick DW, Davis DH (2003) Outcome of trigeminal nerve section in the treatment of chronic cluster headache. Neurology 60(8):1360-1362

37. Lovely TJ, Kotsiakis X, Jannetta PJ (1998) The surgical management of chronic cluster headache. Headache 38(8):590-594

38. Franzini A, Ferroli P, Leone M, Broggi G (2003) Stimulation of the posterior hypothalamus for treatment of chronic intractable cluster headaches: first reported series. Neurosurgery 52(5):1095-1101

39. Leone M, Franzini A, Broggi G, May A, Bussone G (2004) Long-term follow-up of bilateral hypothalamic stimulation for intractable cluster headache. Brain 127:2259-2264

40. Leone M, May A, Franzini A, Broggi G, Dodick D, Rapoport A, Goadsby PJ, Schoenen J, Bonavita V, Bussone G (2004) Deep brain stimulation for intractable chronic cluster headache: proposals for patient selection. Cephalalgia 24(11):934-937 